\title{
The Carbon Sequestration Capacity of Trees Expressed in Monetary Terms
}

\author{
J.C. Jones ${ }^{*, 1}$ and R. Ball ${ }^{2}$ \\ ${ }^{1}$ School of Engineering, University of Aberdeen, UK \\ ${ }^{2}$ Mathematical Sciences Institute, The Australian National University, Canberra ACT 0200 Australia
}

\begin{abstract}
The carbon sequestration potential of trees is expressed in terms of the current monetary value of carbon credits, which is compared to the value of the world oil trade. The global carbon balance is expressed in terms of a thermodynamic/kinetic paradigm.
\end{abstract}

Keywords: Carbon sequestration, carbon credits, oil trade, global carbon balance.

\section{INTRODUCTION}

The first author recently gave a talk at the University of South Africa (UNISA) in Pretoria during which he presented unpublished calculations of his own in which the carbon sequestration function of trees on the planet was estimated in monetary terms and compared in those terms with oil supply. In a letter to the October 2010 issue of the Royal Society of Chemistry's monthly magazine [1] he gave the conclusions of the calculations and offered to e-mail the PowerPoint presentation used in the talk at UNISA to any reader interested in examining the calculations in detail. In the short time since the letter was published there have been no fewer than seventeen requests for the PP presentation, indicating that there is interest in the unpublished calculations. This contribution to OTJ will therefore give the detailed calculations. It is emphasised that they have not been published elsewhere: reference [2] only gave the 'bottom line'.

\section{Background to the Calculations}

The calculations are based on the premise that when there is avoidance of release of one tonne of fossil fuel derived carbon dioxide into the atmosphere a carbon credit has been generated. The price of such credits varies widely and sometimes erratically. The value used in the calculations in the talk at UNISA was $€^{1} 18$ per tonne of $\mathrm{CO}_{2}$ avoided. The presenter of the UNISA talk and first author of this article noted that according to information from NASA photographs the ratio of trees to persons on the planet is about 60 and that the population of the earth is about 7 billion. The presenter/first author therefore used a figure of 400 billion for the total number of trees.

*Address correspondence to this author at the School of Engineering, University of Aberdeen, UK; Tel: + 441224 272793; Fax: + 441224272497

E-mail j.c.jones@abdn.ac.uk

\footnotetext{
${ }^{1}$ Euro
}

\section{Estimation of the Carbon Sequestration Capacity}

One tree takes up about 0.025 tonne of $\mathrm{CO}_{2}$ net in a year [2], thus the total amount taken up in a year $=400 \times 10^{9} \times 0.025$ tonnes. The equivalent carbon credits are worth $€ 18 \times 400 \times$ $10^{9} \times 0.025=€ 180$ billion or $\$$ US 240 billion $^{2}$.

So the trees of the world fulfil a sequestration function worth \$US240 billion per annum.

\section{Comparison with Crude Oil Trading}

Cost of a barrel of oil ${ }^{3}=\$$ US72, therefore $\$$ US240 billion would purchase 3.3 billion barrels. Daily world consumption of crude oil is 85 million barrels, thus 3.3 billion barrels would suffice for 40 days approximately. So the annual carbon dioxide sequestration capacity of the trees is equivalent in monetary terms to oil trading for:

\section{$(40 / 365)$ years $=0.11$ years}

So the sequestration is equivalent to about $10 \%$ of the total world oil trade or about $30 \%$ of the OPEC trade.

\section{Discussion}

The calculations are simple and can be adjusted by readers for other values of a carbon credit and of the price of a barrel of oil. The former fluctuates more than the latter at the present time. The sample calculations above illustrate that the carbon sequestration capacity of the trees is worth a significant proportion of the world trade in oil when each is expressed in a financial paradigm. The sum of $\$ 240$ billion calculated with an annual basis is about $10 \%$ of the 2009 $\mathrm{GDP}^{4}$ of the UK.

It is useful to develop a thermodynamic/kinetic paradigm to describe the impact of fossil fuel burning and the need for carbon sequestration. In this paradigm we can say that the large scale burning of fossil fuels at a furious pace by humans over the past 150 years has jolted the earth's carbon

\footnotetext{
${ }^{2}$ Using the rate of exchange on the day when the calculations were performed.

${ }^{3}$ NYMEX price at the time or preparing the talk in August 2010.

${ }^{4}$ Gross domestic product.
} 
balance out of equilibrium. The rate at which $\mathrm{CO}_{2}$ accumulates in, or is depleted from, the atmosphere is equal to the sum of the rates of carbon transfer between the atmosphere and the various terrestrial and oceanic carbon reservoirs. We can write this equation for the earth's carbon balance succinctly as

$$
\frac{\mathrm{d} c_{a t}}{\mathrm{~d} t}=R_{p h}+R_{r e}+R_{f r}+R_{c h}+R_{f f}+R_{o t},
$$

where $c_{a t}$ is the mass of carbon in the atmospheric $\mathrm{CO}_{2}$ pool, $R_{p h}$ is the rate of carbon uptake by photosynthesis (negative), $R_{r e}$ is the rate of carbon release by respiration (positive), $R_{f r}$ is the rate at which carbon is released by vegetation fires (positive), $R_{c h}$ is the rate at which carbon is sequestered as charcoal (negative), $R_{f f}$ is the rate of carbon release by fossil fuel burning and emissions (strongly positive at present), and $R_{o t}$ is the lumped rate of all other carbon exchange processes (such as oceanic uptake and release, which for this discussion we take as zero).

Some of these rates are known or can be estimated. In $2007 R_{f f}$ was $8 \mathrm{GT} \mathrm{C/year} \mathrm{[3].} \mathrm{A} \mathrm{lower} \mathrm{bound} \mathrm{estimate} \mathrm{for}$ $R_{c h}$ is $-2.31 \mathrm{MT}$ C/year [4]. From above we have the contribution to $R_{p h}$ from trees as $-2.72 \mathrm{GT} \mathrm{C} /$ year. But information is lacking on the qualitative properties of the rate terms in equation (1); i.e., the interdependencies and the exponents wrt $c_{a t}$ and other nonlinearities.

When $R_{f f}$ was zero (i.e., before around 1850 , after which $\mathrm{CO}_{2}$ emissions due to the burning of fossil fuels by humans became significant) the system described by equation (1) was in quasi-equilibrium, or approximate steady state, so that $\mathrm{d} c_{a t} / \mathrm{d} t \approx 0$, although we know that over timescales of tens of millions of years $\mathrm{d} c_{a t} / \mathrm{d} t$ has drifted in slow cycles from positive to negative and back [5]. The current situation is that $R_{f f}$ is positive, large and increasing [3], with the result that $\mathrm{d} c_{a t} / \mathrm{d} t$ is positive and increasing.

We would like to engineer the rates in equation (1) so that $\mathrm{d} c_{a t} / \mathrm{d} t$ again becomes zero, and if we also want to remove the $\mathrm{CO}_{2}$ that fossil fuel burning has deposited into the atmosphere then $\mathrm{d} c_{a t} / \mathrm{d} t$ must be driven negative for some period of time. Thus to restore the earth's carbon balance to quasi-equilibrium we could increase $R_{p h}$, i.e., plant more trees. However the first author's calculation above suggests that we would need to cover the terrestrial surface with 10 times the current number of trees to offset the current $R_{f f}$. So we should also reduce $R_{f f}$ (by using alternative fuels and implementing carbon capture and storage technologies), reduce
$R_{r e}$ (by improved land management), reduce $R_{f r}$ and increase $R_{\text {ch }}$.

Engineering these rates is complicated because they are not independent. For example a recent study indicates that reducing $R_{f r}$ by large scale suppression of vegetation fires actually sequesters more carbon into the atmospheric $\mathrm{CO}_{2}$ pool [4]. This is because $R_{f r}$ is linked to $R_{c h}$ so that suppression of vegetation fires prevents carbon from accumulating in the refractory charcoal pool and enhances the rate of decay or respiration $R_{r e}$.

The generation of carbon credits is equivalent to engineering the rates in equation (1). From the earlier calculation we need to generate about US $\$ 2230$ billion worth of carbon credits per year to cancel out the contribution to the current $R_{f f}$ due to emissions from crude oil consumption.

In conclusion, the case for protecting forests and planting new trees is emphasised by the comparison between their value in terms of carbon credits and the world oil trade. A thermodynamic/kinetic paradigm for the earth's carbon balance is a useful construct that highlights the need for caution and further research. Schemes to geoengineer the earth (such as making and distributing charcoal on a global scale) could backfire (as it were) disastrously unless we can obtain accurate quantitative (how much?) and qualitative (what are the rate functions and nonlinearities?) research data on amounts of carbon in the various carbon reservoirs and carbon transformation rates.

\section{ACKNOWLEDGEMENT}

R. Ball is supported by Australian Research Council Future Fellowship FT0991007.

\section{REFERENCES}

[1] J. C. Jones, "The value of trees", Chemistry World, vol 7, no. 10, p. 34, October 2010.

[2] J. C. Jones, Atmospheric Pollution. Frederickburg: Ventus Publishing, 2008.

[3] US DOE Report DOE/EIA-0484, "International Energy Outlook 2010 - Highlights", May 2010. [Online]. Available: www.eia.doe.gov/ oiaf/ieo/highlights.html < http://www.eia.doe.gov/oiaf/ieo/highlights. html $>$ [Accessed Nov. 29 2010].

[4] R. Ball, "The CharXive Challenge: Regulation of global carbon cycles by vegetation fires". 9 pp., June 2010. [Online]. Available http://arxiv.org/abs/1006.4675 [Accessed Nov. 29, 2010].

[5] P. N. Pearson and M. R. Palmer, "Atmospheric carbon dioxide concentrations over the past 60 million years", Nature, vol. 406, pp. 695-699, August 2000. 